\title{
ПРОБЛЕМЫ МЕТОДОЛОГИИ
}

Удк $378.147 ; 621.3$

\author{
Чапаев Николай Кузьмич \\ доктор педагогических наук, профессор кафедры акмеологии общего и профессио- \\ нального образования Российского государственного профессионально-педагогического \\ университета, Екатеринбург (РФ). \\ E-mail: chapaev- $N$-K@yandex.ru
}

\section{РЕАЛИЗАЦИЯ ДЕЯТЕЛЬНОСТНОГО ПРИНЦИПА В МЕТОДИЧЕСКОЙ КОНЦЕПЦИИ Н. Е. ЭРГАНОВОЙ}

Аннотаиия. Цель статьи - философско-педагогическое осмысление и раскрытие механизмов применения принципа деятельности при решении задач программно-методического обеспечения профессионального образования на основе обобщения научного наследия Н. Е. Эргановой.

Методология иметоды. В основу исследования положена герменевтическая методология. Ведущие методы анализа - интерпретация, осмысление, понимание, а также анализ, сравнение, противопоставление, синтез, обобщение.

Результаты. На основе содержания работ Н. Е. Эргановой создана интерпретационная модель актуализации принципа деятельности при разработ-

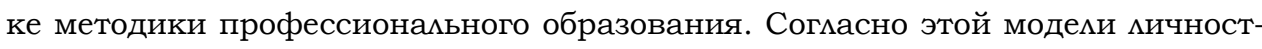
ное и профессиональное становление человека достигается главным образом за счет актуализации его интелмектуального и созидательного потенциала, превращения его в относительно самодостаточного субъекта образовательной деятемьности.

Научная новизна. Раскрыты философско-методологические основы и технологический инструментарий применения принципа деятельности в процессе решения задач программно-методического обеспечения профессионального образования; доказана целесообразность разработки деятельностной стратегии профессионального образования в современных условиях.

Практическая значимость. Положения и выводы статьи могут быть использованы при разработке современной концепции методической деятельности, в процессе программно-методического обеспечения образовательной деятецьности в организациях профессионального образования.

Ключевые слова: деятельность, деятельностный принцип, методическая деятельность, методика профессионального обучения, технологии, объект методической деятельности, предмет методической деятельности, субъекты методической деятельности, виды методической деятельности. 
DOI: $10.17853 / 1994-5639-2016-7-26-39$

Статья поступима в редакцию 25.02.2016.

Принята в печать 28.07.2016.

\title{
Nikolaj K. Chapaev
}

Doctor of Pedagogical Sciences, Professor, Department of Acmeology of General and Vocational Education, Russian State Vocational Pedagogical University, Yekaterinburg (RF).

E-mail: chapaev-N-K@yandex.ru

\section{ACTIVITY-BASED PRINCIPLE IMPLEMENTATION IN THE METHODOLOGICAL CONCEPT OF N. E. JERGANOVA}

\begin{abstract}
The aim of the publication is a philosophical-pedagogical conceptualization and the discovery of the mechanism of application of the principle while solving problems of program-methodological support of vocational education on the basis of summarizing the scientific heritage of N. E. Jerganova.

Methods. The research is based on the hermeneutic methodology. The leading methods of analysis are the following: interpretation, conceptualization, understanding, as well as analysis, comparing, contrasting, synthesis, generalization.

Results. Based on the analysis of the texts of the works of N. E. Jerganova, interpretational model of actualization principle of activity in developing methods of professional education is developed. According to this model, personal and professional development of man is attained primarily due to the actualization of his/her intellectual and creative potential, turning it into relatively self-sufficient entity of educational activity.

Scientific novelty. Philosophical-methodological foundations and technological tools of the application of the principle activities in the process of problem solving of software and methodological support of professional education are disclosed; the expediency of development of activity-based strategy of professional education in modern conditions is proved.

Practical significance. The thesis and conclusions of the article can be used in the development of the modern concept of methodological activities, in the process of program-methodological support of educational activity in professional education organizations.
\end{abstract}

Keywords: activities, activity-based principle, methodical activity, methods of professional training, technologies, object of methodological activities, subject of methodological activity, members of methodological activities, types of methodological activities.

DOI: $10.17853 / 1994-5639-2016-7-26-39$

The article was submitted on 25.02.2016

The article was accepted for publication on 28.07.2016. 
Деятельностный подход - одна из двух важнейших составляющих системно-деятельностного подхода, который является крайне значимым и перспективным методологическим инструментарием развития теории и практики профессионального образования в современный период. Принадлежность деятельностного подхода к привияегированной методомогической доктрине обусловлена во многом его установкой на формирование уже в условиях педагогического процесса целостной инфраструктуры профессиональной деятельности, выражаемой интегральной совокупностью мотивационных, технологических и результирующих составмяющих. Наличием таких возможностей деятельностный подход обязан своему эвристическому первоисточнику - категории деятельности, спеиифической человеческой форме "активного отношения к окружающему миру, содержание которой составляет его иелесообразное изменение и преобразование" [9, с. 151].

Подобная трактовка деятельности позвоцяет ей выступать как

а) объяснительный принцип - понятие с философско-методологическим содержанием, выражающее универсальное основание человеческого мира;

б) предмет объективного научного изучения, т. е. нечто расчценяемое и воспроизводимое в мировой картине в соответствии с методологическими принципами последней;

в) предмет управления, т. е. то, что подлежит организации в систему функционирования и развития;

г) предмет проектирования, т. е. выявление способов и условий оптимальной реализации отдельных видов деятельности;

д) ценность, т. е. рассмотрение места, которое занимает деятельность в разАичных системах культуры [19, с. 272-273].

Не составмяет большой трудности вывести из представменной характеристики деятельности также ряд педагогических следствий. К примеру:

а) деятельность есть конституирующий признак человека - "предмета воспитания" (К. Д. Ушинский), что обусловливает необходимость особого отношения к деятельностному принципу как ведущему методологическому (объяснительному) принципу образования человека;

б) деятельность инициирует активное отношение к миру, что предполагает потребность ее использования как организационного принципа в процессе общего и профессионального развития человека;

в) ориентированность деятельности на иелесообразное изменение и преобразование позволяет использовать ее в качестве предмета проектирования в ходе выработки у обучающихся созидательных и преобразовательных способов освоения действительности и т. д. 
Таким образом, в деятельности происходит становцение продуктив-

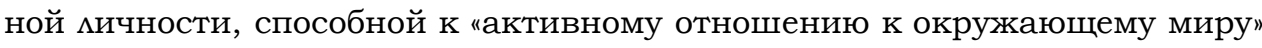
посредством его целесообразного изменения и преобразования. Универсальные качества деятельности позволяют играть также роль уникального системообразующего фактора. «Именно в деятельности, - пишет В. С. Безрукова, - в конечном счете, проявляется сплав общего и профессиональнотехнического образования, их окончательная интеграция" [1, с. 52].

Реализация педагогического потенциала деятельности требует создания соответствующей системы, в основу которой должен быть положен деятельностный принцип. Согласно ему, "усвоение знаний и способов деятельности есть одновременно и процесс, и результат деятельности по разрешению противоречий, содержащихся в изучаемых объектах, понятиях и самом процессе обучения..." [4, с. 184]. Деятельностная компонента должна присутствовать на всех уровнях образовательного процесса - методологическом, теоретическом и практическом. Особое место занимают в нем носители учебно-методического обеспечения, имплицитно "включающие" все названные уровни. Важное срединное значение здесь имеют учебники и учебные пособия. В них, с одной стороны, отражены положения формализованных структур программно-методического обеспечения (стандарты, учебные планы, программы), с другой- представлены содержательные параметры процесса формирования разнокачественных способов деятельности - учебных, учебно-профессиональных, профессиональных. Поэтому очень важна установка на использование в учебниках и пособиях деятельностной стратегии осуществления образовательного процесса.

В работах Н. Е. Эргановой явственно прослеживается деятельностная интерпретация методики профессионального обучения [11-18]. Установка на использование деятельностной стратегии обучения заложена в определении самого предмета методики профессионального обучения. "Предмет познания методики профессионального обучения, - пишет исследователь, - это относительно самостоятельная ветвь педагогических знаний и умений о конструировании, применении и развитии специальных средств обучения, с помощью которых осуществляется регуяяция обучающей деятельности преподавателя (мастера производственного обучения) и когнитивной деятельности учащихся по формированию профессиональных знаний и умений и развитию обучаемых" (курсив наш. H. Ч.) [13, c. 7].

Как видим, в представленном материале утверждается идея деятельностной сущности образовательного процесса. Причем речь идет о межсубъектной (субъект-субъектной) деятельности, а не просто о взаимодействии, как, скажем, в следующем опредемении: "Методика про- 
фессионального обучения - педагогический инструментарий, предназначенный дмя управления процессом усвоения системных профессиональных знаний в данной области деятельности на основе совместного эмоиионально-интеллектуального взаимодействия педагога и обучающихся с учетом их возрастных особенностей, умственных возможностей, а также технического, психолого-педагогического и эргономического обеспечения" (курсив наш. - Н. Ч.) [7, с. 8]. При этом деятельность как бы зависает над совместным взаимодействием и по сути становится бессубъектной.

К сказанному следует добавить, что совместное интеллектуальноэмоциональное взаимодействие отнюдь не предполагает в обязательном порядке совместную деятельность. Здесь правомерно упомянуть формулу Гегеля: одно взаимодействие есть ничто. Чтобы взаимодействие стало чем-то действенно позитивным, необходимо привнесение в него в качестве критериального показателя "значимого компонента" (П. Сорокин). Этот компонент вносит смысл в те или иные взаимодействия. Без него "все половые акты будут идентичными: связаны ми они с проституцией, изнасилованием или супружескими отношениями", без него "мы не сможем сказать, какие реакции явмяются солидарными, а какие антагонистическими, и если все же попытаемся это сделать, то результат будет абсурдным" [8, с. 201, с. 204]. Точно так же без значимого компонента всякий акт педагогического взаимодействия, внешне представмяемый как объединительная операция, может на самом деле быть разъединительным процессом. В качестве "значимого компонента" в нашем случае должна выступить деятельность субъектов образовательного процесса. В их совместной работе, а не по ходу интелмектуально-эмоционального взаимодействия, достигаются в первую очередь общие цели обучения. Говоря о совместной деятельности, нельзя забывать о ее межсубъектном (субъектсубъектном) характере. Да, в совместной (совокупной) образовательной деятельности достигается, в конечном счете, одна цель - общее и профессиональное развитие человека: «обученный учащийся, его система профессиональных знаний и умений, развитая личность и профессиональные способности" $[14$, с. 16]. Но пути к этой цели различны. Если обучающийся как субъект деятельности овмадевает способами учебной, учебно-профессиональной и профессиональной деятельности, то субъект обучающей деятельности (педагог) занят "педагогизацией", "дидактическим препарированием" или "методической редукцией" усваиваемого материала.

Признание наличия бинарной компоненты в образовательной деятельности не отменяет ее метадеятельностной (иерархической) природы. Она выражается в том, что педагог не просто ставит собственные цели, но стремится к тому, чтобы эти цели были осознаны и приняты учащими- 
ся; педагог не просто ищет способы достижения поставменных целей, но и работает над тем, чтобы эти способы были освоены учеником и стали для ученика "своими" [2]. Метадеятельностная (иерархическая) природа отчетливо проявцяется в определении методической деятельности как самостоятельного вида "профессиональной деятельности педагога по проектированию, разработке и конструированию, исследованию средств обучения, позволяющих осуществлять регуляцию обучающей и учебной деятельности по отдельному предмету или циклу учебных дисциплин" [14, с. 23]. Н. Е. Эрганова конкретизирует ведущую роль педагога как проектанта, разработчика и конструктора средств регулирования собственной обучающей деятельности и деятельности обучающегося.

Об актуализации деятельностного принципа в методической концепции Н. Е. Эргановой свидетельствует и глубокая проработка понятия "методическая деятельность". Одну из своих работ она знаково назвала "Феномен методической деятельности в условиях становления и развития технологии обучения" [17]. Исключительно большое внимание понятию "методическая деятельность" автор уделяет в своих учебных пособиях [см., например, 13, 14]. Деятельностная концепция методики профессионального обучения является у Н. Е. Эргановой плодом ее многолетних раздумий и научных поисков, а не предметом случайного интереса к "модному" принципу, что позволило ей создать оригинальную систему научно-методического обеспечения методики профессионального обучения на деятельностной основе.

Н. Е. Эрганова подвергла глубокому анализу сущностные, функциональные и морфологические характеристики методической деятельности педагога профессионального образования [13, 14, 17, 18]. Сущность выражена в приведенном выше определении предмета методической деятельности. Функционал методической деятельности включает в себя анацитическую, проектировочную, конструктивную, нормативную и исследовательскую функции. В своей совокупности они образуют вертикаль значений и действий, выражающих суть методической деятельности.

Морфологическое строение методической деятельности составцяют внутренняя и внешняя подструктуры. Внутреннюю подструктуру образуют объект, предмет, субъект и результаты (продукты). В качестве объекта методической деятельности педагога профессиональной школы автор обозначила "процесс формирования профессиональных знаний, умений и навыков" [14, с. 22]. Сегодня может появиться желание вместо знаний, умений и навыков вставить "компетенции". Но это будет отражать не столько действительные потребности онтологии нашего образовательного бытия, сколько потребности его гносеологии, ангажированной знаковыми проявцениями времени. Это во-первых. 
Во-вторых, практически всякая компетенция, так или иначе, "переводится" как некий набор знаний, умений и навыков - знать, уметь, владеть. На наш взгляд, директивное насаждение понятия "компетенции" в категориальном и методологическом аппарате нашей педагогики в наблюдаемых сегодня масштабах и смыслах непродуктивно, а возможно, даже вредно. По меньшей мере, такое насаждение противоречит принципу Оккама, "не следует привлекать новые суиности без самой крайней на то необходимости".

В-третьих, в статье 2 "Основные понятия, используемые в настоящем Федеральном законе" Закона об образовании РФ (2012) профессиональное обучение трактуется "как вид образования, который направлен на приобретение обучающимися знаний, умений, навыков и формирование компетенций, необходимых для выполнения определенных трудовых, служебных функций (определенных видов трудовой, служебной деятельности, профессий)...". Как видим, не сильно почитаемые в наши дни ЗУНы в Законе не проигнорированы. Да и мудрено их игнорировать. На одних "голых" компетенциях учебный процесс не построишь. Пусть даже они будут "золотыми" по содержанию, форме, амбициям. Без знаний, умений и навыков ничего не сформируешь. А без обозначающих их понятий никак нельзя объяснить, что все же "сформировали у обучающихся»? Чтобы это понять, компетенции “переводятся" на нормальный педагогический язык при помощи тех же почти проклинаемых сегодня знаний, умений и навыков. Есть все основания утверждать: компетенции без зУНов не могут обходиться, а ЗУНы без компетенций - могут. Точно так же, как они обходимись до сей поры не одно тысячелетие.

В содержание предмета методической деятельности Н. Е. Эрганова вкАючает приемы, методы, способы реализации и регуляции процесса формирования новых знаний и умений с учетом специфики содержания конкретного предмета. Это также вполне правомерно и конкретно, если исходить из требований естественной, а не виртуальной, директивной, реальности.

Что касается состава субъектов методической деятельности, представценных в работах Н. Е Эргановой, то, с нашей точки зрения, он не полон и в какой-то мере противоречит бинарной концепции методической деятельности самой Н. Е. Эргановой. Выше мы отметили, что в этой концепции речь идет не только о межсубъектном, но и о междеятельностном процессе, соответственно - об обучающей и об учебной деятельности. Следовательно, должны быть выделены субъекты обучающей деятельности и субъекты учебной деятельности. Но мы читаем: "Субъектами методической деятемьности явцяются педагог ими комлектив педагогов" $[13$, с. $14 ; 14$, с. 22$]$. 
Всякая деятельность "красна" результатами. Не составляет исключения и методическая деятельность. В состав ее результатов входят алгоритмы решения задач; мисты рабочей тетради; приемы, методы обучения; обучающие программы и др. Правомерно к результатам (продуктам) методической деятельности причислить и новообразования в Аичности обучающегося, формирующиеся в ходе образовательной деятельности. Это в полной мере соответствует деятельностной сути концепции методики профессиональной обучения, разработанной Н. Е. Эргановой.

Внешняя морфология методической деятельности в трудах Н. Е. Эргановой представлена видами данной деятельности. Понимая под ними "устойчивые процедуры осуществления планирования, конструирования, выбора и применения средств обучения конкретному предмету, обусловмивающие их развитие и совершенствование" [14, с. 24], она к ним относит методический анализ учебного материала; планирование системы уроков теоретического и практического обучения; моделирование и конструирование форм предъявления учебной информации на уроке; конструирование деятельности учащихся по формированию технических понятий и практических умений; рефлексию собственной деятельности при подготовке к уроку и при анализе его результатов и др.

Перечень вовсе не есть замкнутый в себе набор формализованных статичных данных. Его составляющие самым тесным образом соотносятся с тремя группами умений - умениями, связанными с овладением дидактико-методическими основами профессиональной деятельности педагога профессиональной школы; умениями, учитывающими специфику учебного материала; умениями, синтезирующими ранее сформированные умения [13, с. 15].

Если внимательно присмотреться, то можно с полным основанием заявить: эти умения ничем не хуже компетенций. Например, стоит в первом попавшемся "умении проводить анализ учебно-программной документации по обучению специалиста" заменить слово "умение" на спасительное словечко "Готовность" (или "способность"), и мы получим самую что ни на есть настоящую компетенцию: готовность проводить анализ учебно-программной документации. Это умение первой группы. Возьмем умение третьей (посмедней) группы: «Умение применять методические рекомендации, методики и техномогии обучения на практике». Проведите ту же операцию с заменой слов и получите тот же "компетентностный" результат.

Доказательством реализации деятельностного подхода в концепции Н. Е. Эргановой скужит также построение инфраструктуры методической деятельности. Подробно раскрывая функционал последней, Н. Е. Эрганова создает цельную систему видов деятельности. Эта система вбирает в себя аналитический, проектировочный, конструкторский, диагностический типы деятельности. Значительной научно-методической и практи- 
ческой ценностью обладает технология методического анализа, разработанная Н. Е. Эргановой. Внутри же этой технологии, на мой взгляд, особое место занимает методическая редукция - "...трансформация абстрактных теоретических положений научной области соответственно уровню понимания учащихся" [13, с. 67].

Методическая редукция - это своего рода "третья ступень" педагогической редукции. Первая ступень - педагогизация. В широком смысле слова ее «можно охарактеризовать как процесс приобретения инородным объектом (явиением, процессом) педагогических качеств" [10, с. 170]. На уровне научно-педагогического знания в свое время выдающийся педагог-методолог В. С. Гмурман охарактеризовал педагогизацию как «ассимиляцию педагогикой инонаучных данных в русле своего предмета" [5, с. 55]. Вторая ступень педагогической редукции - "дидактическое препарирование" (Э. Ф. Зеер): переформатирование (структурирование и систематизация) научно-технического текста в дидактически обоснованный учебный материал.

Следуя могике деятельностного подхода, правомерно заявить, что всякие действия с учебным материалом непременным образом непосредственно или опосредованно касаются субъектов образовательной деятельности. И, главным образом, субъекта учебной деятельности. Манипулируя с инфраструктурными эмементами учебного материала, педагог домжен ясно представ ять их последствия дия мичности данного субъекта. Еще в работе 1990 года издания Н. Е. Эрганова пишет о доминировании в методике профессионального обучения вопроса о трансформации содержания учебного материала "в знания, умения учащихся" [15, с. 8].

Н. Е. Эрганова указанный выше вопрос рассматривает в широком контексте. Она не ограничивается критерием эффективности трансформации учебного материала. Она не ставит задачу как можно больше учебного материала переформатировать в ЗУНы. Для нее важно, как эта трансформация осуществляется и как она отразится на мичности. Развивая учение о методической редукции, Н. Е. Эрганова демонстрирует цецую систему приемов данной трансформации, ориентированных на комфортное ее осуществление, что не в последнюю очередь достигается за счет введения критериев психологического и эргономического характера. $\mathrm{K}$ тому же эти приемы носят инверсионный характер в том смысле, что они явцяются средствами и обучающей, и учебной деятельности. Это демает просто необходимым учет мичностной компоненты в структуре последней, что как раз характерно для методической системы Н. Е. Эргановой $[11$, с. 131-142].

К сожалению, сегодня, в эпоху сплошной стандартизации и бесконечных пертурбаций в образовании, мало кто из нас, педагогов, останавцивается, чтобы оглянуться вокруг, засомневаться в своих действиях, задаться вопро- 
сом: а все ми мадно мы демаем? Кстати, еще в первой трети прошлого века "социократ" и "технократ" А. С. Макаренко задавался подобного рода вопросом, правда, применительно к сфере воспитания: «Что же я, должен вгонять каждую индивидуальность в единую программу, в стандарт и этого стандарта добиваться? Тогда я должен пожертвовать индивидуальной прелестью, своеобразием, особой красотой мичности, а если не пожертвовать, то какая же у меня будет программа!». Где же выход? А. С. Макаренко находит его в диалектическом решении проблемы: нужны и общая, "стандартная" программа, и "индивидуальный корректив" к ней, т. е. программа индивидуального развития дмя каждого [3, с. 118-119, с. 353].

Примером реализации деятельностного подхода к методике профессионального обучения явцяется разработка Н. Е. Эргановой технологического инструментария методики профессионального обучения $[11,18]$. В настоящее время, в эпоху педагогического конструктивизма, проблемы педагогической технологии выдвинулись на первый план. При этом значительную актуальность приобретают в педагогике вопросы соотносительной идентификации категорий “методика" и "технология". Здесь нашлось место различным толкованиям. Так, методика представляется как совокупность способов организации педагогического процесса, а технология - как средства их реализации. Соответственно, в системе "методика технология" первая выступает преимущественно как форма, вторая - как содержание. Сиучаются и иные варианты [6, 14, с. 48-54]. Дия нас особую ценность представляет признание Н. Е. Эргановой того, "что инструментальный характер методик обучения наиболее отчетливо и ярко проявляется в педагогических технологиях" [11, с. 54]. Некоторое переосмысление данной формулы дает нам возможность сделать вывод о том, что технологический этап развития методики в целом и методики профессионального обучения в частности является качественно новой ступенью реализации деятельностного принципа в педагогике. По словам Н. Е. Эргановой, "педагогические технологии стоят значительно выше по свойству и уровню организации педагогического процесса" [11, с. 54]. Ярким свидетельством этому служит материал цитируемой нами монографии “Введение в техномогии профессионамьного обучения" [11]. В ней, как нигде, образуют единое целое методика, технология и деятельность, скрепляемые целями мичностно-субъектного и профессионального развития человека.

В заключение отметим следующее:

1. Деятельностная стратегия профессионального образования обладает мощным потенциалом, востребованным вызовами общего и профессионального развития современного человека.

2. В концепции методики профессионального обучения осуществлена реализация деятельностного подхода путем деятельностной интерпре- 
тации сущностных и морфологических характеристик данной методики, разработки эффективной технологической базы их реализации.

3. Дальнейшее развитие деятельностной парадигмы образования не будет достаточно успешным без реалистического осмысления происходящих сегодня образовательных событий, при которых во главу угла ставятся переписанные зарубежные образцы. Внутри страны мы истово ведем борьбу с плагиатом и в то же время активно занимаемся списыванием закордонных образовательных мудростей. Но в таком случае следовало бы подумать: чего ради нас так щедро угощают бесплатным образовательным ширпотребом? Ведь уже не одно десятиметие постоянно смышим: бесплатным сыр бывает только в мышеловке. Человечество же вообще уже не одно тысячелетие твердит: бойся данайцев... Но еще важнее то, что мы привыкаем к репродуктивному воспроизводству готовых образцов, что неминуемо ведет к падению нашего творческого созидательного тонуса.

Статья рекомендована к публикаиии д-ром пед. наук, проф. Е. М. Дорожкиньм

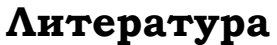

1. Вопросы взаимосвязи общеобразовательной и профессионально-технической подготовки молодых рабочих: сборник научных трудов. Москва: АПН СССР, 1982. 144 c.

2. Кулюткин Ю. Н., Сухобская Г. С. Моделирование педагогических ситуаций. Москва: Просвещение, 1981. 120 с. $540 \mathrm{c}$

3. Макаренко А. С. Сочинения: В 7 т. Москва: АПН СССР, 1951. Т. 5.

4. Махмутов М. И. Проблемное обучение: основные вопросы теории. Москва: Педагогика, 1972. 368 с.

5. Методомогические проблемы развития педагогической науки / под ред. П. Р. Атутова, М. Н. Скаткина, Я. С. Турбовского. Москва: Педагогика, 1985. $240 \mathrm{c}$.

6. Основы педагогических технологий: краткий толковый словарь / отв. ред. А. С. Белкин. Екатеринбург, 1995. 22 с.

7. Скибицкий Э. Г., Толстова И. Э., Шефель В. Г. Методика профессионального обучения: учебное пособие. Новосибирск: НГАУ, 2008. 166 с.

8. Сорокин П. А. Цивилизация. Общество: пер. с англ. / общ. ред., сост. и предисл. А. Ю. Согоманова. Москва: Политиздат, 1992. 543 с.

9. Философский энциклопедический словарь. Москва: Советская энцикмопедия, 1983. 840 с.

10. Чапаев Н. К., Вайнштейн М. $\Lambda$. Интеграция образования и производства: методомогия, теория, опыт: монография. Челябинск; Екатеринбург: ЧИРПО; ИРРО, 2007. 408 с. 
11. Эрганова Н. Е. Введение в технологии профессионального обучения: монография. Екатеринбург: РГППУ, 2009. 151 с.

12. Эрганова Н. Е. Методика профессионального обучения в системе современного педагогического знания // Профессиональная педагогика: категории, понятия, дефиниции: сборник научных трудов. Вып. 3. Екатеринбург, 2004. С. 475-489.

13. Эрганова Н. Е. Методика профессионального обучения: учебное пособие. 3-е изд., испр. и доп. Екатеринбург: РГППУ, 2005. 150 с.

14. Эрганова Н. Е. Методика профессионального обучения: учебное пособие дия вузов / Н. Е. Эрганова. Москва: Академия, 2008. 159 с.

15. Эрганова Н. Е Основы методики профессионального обучения: учебное пособие дия инженеров-педагогов эмектротехнического профиця. СвердАовск: СИПИ, 1990. 148 с.

16. Эрганова Н. Е. Развитие концепций подготовки педагога профессионального обучения // Вестник Учебно-методического объединения по профессионально-педагогическому образованию: сборник научных трудов. Екатеринбург: РГППУ, 2009. Вып. 1 (43). С. 32-41.

17. Эрганова Н. Е. Феномен методической деятельности в условиях становления и развития техномогии обучения // Повышение академического уровня учебных заведений на основе новых образовательных технологий: в 3 ч. Ч. 1. Тезисы докладов Российской научной практической конференции по инновациям в профессионально-педагогическом образовании, 24-28 ноября 1997 г. Екатеринбург: УГППУ, 1997. С. 83-86.

18. Эрганова Н. Е., Шалунова М. Г., Колясникова $\Lambda$. В. Практикум по методике профессионального обучения: учебное пособие. 2-е изд. Екатеринбург: РГППУ, 2011. 89 с.

19. Юдин Э. Г. Системный подход и принцип деятельности. Москва: Наука, 1978. 272 с.

\section{References}

1. Voprosy vzaimosvjazi obshheobrazovatel'noj i professional'no-tehnicheskoj podgotovki molodyh rabochih. [The relationship of general education and vocational training of young workers]. Sbornik nauchnyh trudov. [Collection of scientific papers]. Moscow: APN USSR, 1982. 144 p. (In Russian)

2. Kulyutkin J. N., Suhovskaya G. S. Modelirovanie pedagogicheskih situacij. [Modeling of pedagogical situations]. Moscow: Publishing House Prosveshhenie. [Education]. 1981. 120 p. (In Russian)

3. Makarenko A. S. Sochinenija: V 7 tomah. [Ouvre. In 7 volumes]. Vol. 5. Moscow: APN USSR, 1951. 540 p. (In Russian)

4. Makhmutov M. I. Problemnoe obuchenie: osnovnye voprosy teorii. [Problem-based learning: Basic theory]. Moscow: Publishing House Pedagogika. [Pedagogy]. 1972. 368 p. (In Russian)

5. Metodologicheskie problemy razvitija pedagogicheskoj nauki. [Methodological problems of teaching science]. Ed. by P. R. Atutov, M. N. Skatkin, J. S. Turbovsky. Moscow: Publishing House Pedagogika. [Pedagogy]. 240 p. (In Russian) 
6. Osnovy pedagogicheskih tehnologij. [Fundamentals of educational technology]. Edited by A. S. Belkin. Ekaterinburg, 1995. 22 p. (In Russian)

7. Skibitskiy E. G., Tolstov J. D., Shefel V. G. Metodika professional'nogo obuchenija. [Methodology of the vocational training]. Novosibirsk: NGAU, 2008. 166 p. (In Russian)

8. Sorokin P. A. Civilizacija. Obshhestvo. [The Civilization. Society]. Translated from English. Ed. by A. Y. Shamanova. Moscow: Publishing House Politizdat, 1992. 543 p. (In Russian)

9. Filosofskij jenciklopedicheskij slovar'. [Encyclopedic dictionary of philosophy]. Moscow: Publishing House Soviet Encyclopedia. 1983. 840 p. (In Russian)

10. Chapaev N. K., Weinstein M. L. Integracija obrazovanija i proizvodstva: metodologija, teorija, opyt. [Integration of education and production: methodology, theory, experience]. Chelyabinsk; Ekaterinburg: ChIRPO; IRRO, 2007. 408 p. (In Russian)

11. Jerganova N. E. Vvedenie v tehnologii professional'nogo obuchenija. [Introduction to the technology of training]. Ekaterinburg: RGPPU, 2009. 151 p. (In Russian)

12. Jerganova N. E. Methods of professional training in the system of modern pedagogical knowledge. [Professional'naja pedagogika: kategorii, ponjatija, definicii: sbornik nauchnyh trudov]. Professional Pedagogics: Categories, Notions, Definitions: Collection of Scientific Papers. Ekaterinburg: RGPPU, 2004. Vol. 3. P. 475-489. (In Russian)

13. Jerganova N. E. Metodika professional'nogo obuchenija. [The methodology of vocational training]. 3rd edition. Ekaterinburg: RGPPU. 2005. 150 p. (In Russian)

14. Jerganova N. E. Metodika professional'nogo obuchenija. [The methodology of vocational training]. Moscow: Publishing House Akademija. [Academy]. 2008. 159 p. (In Russian)

15. Jerganova N. E. Osnovy metodiki professional'nogo obuchenija. [Basis of methods of vocational training]. Sverdlovsk: SIPI, 1990. 148 p. (In Russian)

16. Jerganova N. E. Vestnik uchebno-metodicheskogo ob'edinenija po professional'no-pedagogicheskomu obrazovaniju: sbornik nauchnyh trudov. [Development of concepts for training teachers of vocational training]. Bulletin of Educational and Methodical Association of Professional Pedagogical Education: Collection of Scientific Papers. Ekaterinburg: RGPPU, 2009. Vol. 1 (43). P. 32-41. (In Russian)

17. Jerganova N. E. The phenomenon of the methodological activity in the conditions of formation and development of learning technologies. Povyshenie akademicheskogo urovnja uchebnyh zavedenij na osnove novyh obrazovatel'nyh tehnologij: $v 3 \mathrm{ch}$. Ch. 1. Tezisy dokladov Rossijskoj nauchnoj prakticheskoj konferencii po innovacijam $v$ professional'no-pedagogicheskom obrazovanii, 24-28 nojabrja 1997. [Increase of the Academic Level of Educational Institutions on the Basis of New Educational Technologies. In 3 parts. Part 1. Thesis of Scientific and Practical Conference on Innovation in Vocational-Pedagogical Education, d.d. 24-28 November, 1997, Ekaterinburg]. Ekaterinburg: UrGPPU, 1997. P. 83-86. (In Russian) 
18. Jerganova N. E., Shalunova M. G., Kolyasnikova L. V. Praktikum po metodike professional'nogo obuchenija. [Workshop on vocational training]. Ekaterinburg: RGPPU, 2011. 89 p. (In Russian)

19. E. G. Yudin. Sistemnyj podhod i princip dejatel'nosti. [Systematic approach and principle of activity]. Moscow: Publishing House Nauka. [Science]. 1978. 272 p. (In Russian) 